\title{
A Tentative Discussion on the Constraints on Production and development of Cotton and Countermeasures
}

\author{
Tan Hong, Ma Qiong \\ College of Economic and Management of Xinjiang Tarim University, Alear City, Xinjiang, 843300
}

Keywords: Cotton, production and development, constraints, solving policy.

\begin{abstract}
As an important cash crop, cotton is of far-reaching signficance for development of Chinese economy. Besides, in China which is a big agricultural power, the production and development of cotton occupies a prominent position. However, the presence of some constraints on production and development of cotton severely hinders cotton from boosting agricultural economy. Thus it is very pressing to solve these problems in agricultural production and development in China. The paper first analyzes the importance of production and development of cotton, followed by delving into the constriants on production and development of cotton, and lastly, it emphantically explores the countermeasures against the constraints, in an effort to provide a reference frame for future research on this domain.
\end{abstract}

\section{Introduction}

Coupled with growing trend of economic globalization, the economic tie among countries across the world is increasingly closer. As an important member in this "big world family", China naturally cannot be independent of the influence of economic globalization, especially after China joined WTO, the economic globalization has caused more profound impact. A wide view of current development of world economy shows escalation of demands for cotton, thereby bringing opportunities to production and development of cotton in China. Nevertheless, the production and development of cotton also faces acid test with substantial increase of work force and everexpanding of cotton planting scale. This backdrop entails to analyze current difficulties in production and development of cotton to make proper adjustment so as to confront the challenges.

\section{Constraints on production and development of cotton}

Production cost goes high continuously. The production of cottol involves heaps of factors, such as work force, resources and market, etc. Recent years witnessed cost rise of various factors, while the increase rate of cotton price goes in a direction reverse to the relentless increase of the factors' cost. The government's strong support in cotton plantation still fails to conceal the everincreasing of cotton's production costs, which naturally reduces economic benefit. Take the cotton industry in Xinjiang for example, in terms of the production factor of work force, the per hectare production costs of cotton averagely increased from original 4,350 Yuan to later 15,000 Yuan during the two decades from 1990 to 2009.[1]

Instable market price of cotton. The instable market price of cotton also constrains production and development of cotton. The growing trend of economic globalization connects different economies more tightly, and the economic fluctuation in individual regions tends to send ripples to the cotton market. As the cotton industry is intensive, the developed countries in the west take advantage of the intensive operation of cotton production to expand share in the international market of cotton wool, which greatly hits Chinese cotton industry.[2]The instable world economy and potential economic crisis influences the competitive edge of cotton's industry chain such as textile industry, thereby causing instable demands for cotton to directly fluctuate violently the market price of cotton.

Severe diseases and pests. Like other crops, the cotton plantation inveitably suffers from 
diseases and pests. The diseases and pests have always been largely influencing the production and development of cotton. Take Xinjiang for example, the cotton plantation is often impacted by wilt and cyanosis, which is very prevelent in Xinjiang.[3]. Once wilt and cyanosis occur, the cotton is hard to resist, thereby significantly lowering ouput of cotton. Besides, cotton plantation in some area also faces resouces shortage, such as water. Althought cotton plantation does not need too many water resources, a wide view of cotton plantation in China shows that the northwest China is short of water severely.

Problematic cotton quality.

Quality is another factor obviously influencing the production and development of cotton. In fact the cash crop is a commodity, whose exchange obeys the rule of exchange of equivalents, while in exchange of equivalents, the value of the commodity plays a decisive role [4]. The importance of quality speaks for itself among the factors influencing value of commodity. Currently, the quality problem has always been very outstanding in Chinese production and development of cotton and finds expression in many aspects, such as single quality character, inconsistent quality character, severe pollution by heterogenous fibre and impurities, lack of high quality cotton wool, etc., which directly impairs cotton quality and influences production and development of cotton.

\section{Countermeasures for production and development of cotton}

Mechanized production and industralized operation. Mechanized production and industrialized operation are the trend of modern agriculture. Generally Chinese scale of cotton plantation is not prodigious, but is concentrated in Xinjiang and middle-lower Yangtze river reaches. Further improvement on benefit of cotton production and development entails to put efforts in expanding plantation scale. Mechanized picking and industralized operation must be implemented in the process of adjusting layout of cotton industry and expanding plantation scale. Thus, for the cotton plantation, we can actively learn advanced foreign picking technology and plantation management technology, effectively utilize professional picking tools to raise picking efficiency and cut picking cost. Industralized operation is also an important aspect to raise the benefit of cotton production and development. Despite a certain market system formed for production and development of cotton in China, it is not perfect enough and extremely prone to swing with market fluctuation [5]. To realize industrialized operation of cotton, we can encourage and support the textile enterprises in establishing production base of raw material in cotton production area to drive a great many households to plant cotton and realize standard production. In some parts where conditions are ripe, economic complexes integrating trade, production and agriculture and merging production and sale can be established, to develop order production and push industrialized operation of cotton.

Take countermeasures to reduce the production costs. The benefit of cotton plantation directly determines the benefit of cotton production, so raising benefit of cotton plantation is of strong strategical significance for cotton production. Previous content repeatedly states that the countries got involved in the "economic warfare" in succession against the background of economic globalization. To improve competitive edge in the "warfare" and occupy an advantageous spot need to proceed with cotton output and make great efforts at yield of per unit area, benefit of cotton plantation and cost reduction. Thus, we should take active measures to reduce the production costs. Concretely, we should popularize cotton plantation technologies and increase cotton output. If condition permits, some parts may attempt at multistoried planting of cotton field, in an effort to increase the proportion of two cropping and three croppying cotton field to over $60 \%$ of cotton field. ${ }^{[6]}$ Besides, the resources must be economized effectively, no matter water, labor or fertilizer, we must place a high premium on them. Economization of resources is a direct way to cut cost.

Enhance scientific research efforts to improve quality of cotton wool. The above context has mentioned the necessity of improving cotton quality to reduce the production costs. As quality is a factor greatly influencing the production and development of cotton, so this aspect is mentioned emphantically here. Quality guarantee is needed for any product, especially the international market of cotton wool requires high on quality. To be recognized by the international market of cotton 
wool, we must improve quality painstakingly. First measure is popularizing leading varieties [7]. Qulity is often closely related to varieties, as the cotton variety is an intrinsic factor determining the quality of cellulose. Second measure is optimizing matching cultivation techniques. The culture of cotton must be strictly managed. The last measure is controlling picking and transporting of cotton. As a matter of fact, the implementation of above concrete countermeasures must depend on scientific research. For example, cultivation of varieties requires more scientific research efforts from the related government departments to develop better cotton varieties. Another example is that the cultivation technology of cotton requires improvement on innovation ability and cultivation techniques.

Enhance supervision and control and raise government subsidy. The government should give rein to own function and play own part by enhancing control and supervision over cotton market. In supervision and control, the government should lead the development of cotton market and see clearly the government's positioning in the market against the backdrop of market economy. To be brief, the governement should not rigidly manage or deregulate completely the cotton market, but should bring it well under control. ${ }^{[8]}$ In the aspect of government subsidy, the government should raise subsidy standard and increase subsidy items. The improvement on subsidy standard of cotton serves as embodiment of policy support and can produce a signficant effect on stability of cotton market and enthusiasm for cotton plantation. In addition, the government should also raise the subsidy standard for improved crop strains. In recent years, the government has improved this standard much. To further enhance international competition capability of Chinese cotton, the input in subsidy for improved crop strains should be increased further, so as to boost production and development of cotton.

Prevent and control diseases and pests. The cotton plantation is always persecuted by diseases and pests, which, though cannot thorougly solves, must be prevented and controlled in cotton plantation to minimize the harm. Following aspects of work must be done for insect disease prevention: firstly, popularize leading varieties and raise planting level. This has been mentioned early, here no more statement is provided. Secondly. Conduct well routine management. The managment efforts must be sufficient in cotton production and countermeasurs should be timely adopted in case of finding diseases and pests. Thirdly, treatment of diseases and pests. Effective countermeasures should be taken when diseases and pests occur, including physical mode or biochemical mode, to nip diseases and pests in the bud and reduce the related economic losses.

Polish the service system of cotton technology transfer. The government should put in more promotion expenses, stablize grass-roots team, polish the popularization system of agricultural technology, intensify technology popularization, establish and perfect servic system of cotton technology transfer. The best part of cotton planters are willing to follow national policies, as the national policies can give them tangible benefits. In the eyes of cotton planters, the servic system of cotton technology transfer is a policy benefiting farming and deserves active response, thereby improving their enthusiasm of cotton plantation. In the meanwhile, we should fully train the cotton planters and popularize the technology, to make them learn and master more advanced technique of cotton plantation and raise yield of per unit area.

\section{Conclusion}

In summary, cotton is an all-important cash crop and its production and development are of crucial importance to national economy. The various subjective and objective factors, such as too high production costs, instable market price, too many diseases and pests, cotton quality, etc., largely restrict the production and development of cotton. Thus, we should adopt corresponding measures. Considering the actual conditions of cotton production and development, we should enable mechanized production and industrialized operation to augment economic benefit of cotton industry and enhance input to improve plantation of cotton. The government should also give full play to its role by regulating and controlling the cotton market and polishing service system for cotton technology transfer. The cotton planters should prevent and control diseases and pests to make cotton grow smoothly. 


\section{References}

[1] Rouzi.Maimaiti. Tursun. A Brief Analysis on the Factors Constraining Development of Xinjiang's Cotton Industry and Countermeasures [J]. Rurai Science \& Thchnology ,2011,24(10):7071.

[2] Yang Fen, Wei Fusheng, Qu Fei, et al. The Problems in Cotton Production in Shanxi and Countermeasures [J]. Journal of Shanxi Agricultural Science. 2011,36(09):1032-1034.

[3] Cao Dihuan, Guo Bin. A Tentative Discussion on the Problems of Cotton Production and Countermeasures [J]. Chinese Cotton and Jute Circulation Economy ,2011,74(04):19-20.

[4] Yu Qianxian. The Problems in Cotton Production and Countermeasures [J]. Modern Agricultural Science And Technology. 2011,86(02):105+108.

[5] Kong Qingping. An Analysis on the Key Factors Constraining the Production and Development OF Cotton in Xinjiang and Exploration into the Countermeasures [J]. Xinjiang Agricultural Sciences ,2010,27(S2):3-5.

[6] Yang Xiliang, Yang Aihua, Cheng Guofu. Constriants on Sustainable Development of Cotton Production in Dongying and Countermeasures [J]. China Seed Industry, 2007,103(02):44-45.

[7] Sun Chunmei, Tang Yuxuan. The Constraints on Sustainable Development of Cotton Production in Kaifeng and Countermeasures [J]. China Cotton. 2006,41(09):41-42.

[8] Xu Jun. The Problems in Cotton Production in Dunhuang and Developments Countermeasures [J]. Agricultural Science-Technology and Information, 2010,24(15):14-15. 